DOI: $10.17805 /$ zpu.2017.3.17

\title{
Отражение эпоса и преданий в древнейших памятниках славяноязычной литературы: к методологии выявления*
}

\author{
С. В. АЛЕКСЕЕВ, О. А. ПЛОТНИКОВА
}

ИСТОРИКО-ПРОСВЕТИТЕЛЬСКОЕ ОБЩЕСТВО «РАДЕТЕЛЬ», Г. МОСКВА

Статья посвящена методам вычленения элементов устного происхождения в письменных памятниках. Цель статьи - дать обзор известных в науке методов на материале славянских литератур раннего Средневековья, выявить степень их применимости с позиций современного научного знания. В науке традиционно применяются источниковедческий анализ происхождения тех или иных сведений в нарративных памятниках (прежде всего о ранней истории); анализ жанровых особенностей целых памятников (напри-

* Статья подготовлена при финансовой поддержке РФФИ (грант № 17-06-00008А, «Устная историко-эпическая традиция в древнейших памятниках славяноязычной литературы»).

The article was prepared with the financial support of the Russian Foundation for Basic Research (Grant No. 17-06-00008A, «Oral historical-epic tradition in the oldest monuments of Slavonic literature»). 
мер, эпического характера) и отдельных фрагментов; сопоставление сюжетов и мотивов, отмеченных в письменных памятниках, с фольклорными сюжетами и мотивами; выявление стилистических и лексических особенностей, сближающих письменный памятник или его фрагменты с фольклором. В то же время исследования последних десятилетий показали слабые стороны прямолинейно-упрощенного подхода к выявлению фольклорных элементов в средневековой славянской словесности, вероятность книжного происхождения многих сюжетов и мотивов, ранее безапелляционно относимых к числу фольклорных.

Обращается внимание на узость грани, отделяющей книжно-литературное творчество от устно-эпического (отсутствие на ранних этапах развития словесности осознанного авторства, общие для ранней книжности и фольклора механизмы уподобления реального идеальному и образцовому). Все это побуждает исследователей, акцентирующих внимание на устных источниках славянской словесности, скорректировать методику с учетом достижений коллег - прежде всего это касается необходимости более тщательного исследования текстов иноязычного происхождения, которые были или могли быть источниками славянских книжников.

Более четкие критерии вычленения элементов устной традиции из письменных памятников могут быть основаны только на сочетании методов филологических (исследование особенностей эпической «речи») и источниковедческих (вычленение элементов, заведомо не имеющих книжного прототипа, в древнейших сочинениях исторического содержания).

Ключевые слова: эпос; предание; устная традиция; фольклор; древнерусская литература; южнославянская литература; Средневековье; летописание; жития; источниковедение

\section{ВВЕАЕНИЕ}

$\mathrm{T}$ ематика, связанная с исследованиями устной традиции, «устной истории», а также взаимодействия устной традиции и книжности, является активно разрабатываемой и дискутируемой в отечественной и мировой науке. В частности, и в памятниках средневековых славянских литератур исследователи давно видят элементы, восходящие к устной традиции. Изучением этой проблематики занимались несколько поколений историков и филологов как в славянском мире, так и за его пределами начиная с первых десятилетий развития критической научной мысли.

В то же время проблема методов выявления таких элементов, действительно, остается полем научных дискуссий, подчас весьма острых. На протяжении уже более чем двух столетий ключевым дискуссионным вопросом остается соотношение исторических и филологических методов. При этом «исторический» и «филологический» в данном контексте было бы гораздо уместнее помещать в кавычки. Ясно, что без взаимопроникновения методик исторической и филологической наук невозможен даже подступ к решению описываемой научной задачи. Проблема скорее состоит в степени овладения представителями дисциплин методами друг друга, в способности выработать междисциплинарный подход. Решение проблемы несколько облегчил наметившийся к концу ХХ в. культурологический синтез, однако он сам в значительной степени все еще остается утопией.

Аругим, не менее острым поводом для дискуссий, особенно последних нескольких десятков лет, является смешение проблем происхождения и достоверности тех или иных известий раннеписьменной традиции. В основе его лежит наследие научных споров XIX в., в ходе которых взаимосвязанность этих проблем была необоснованно преувеличена. Скептическая традиция ранней европейской науки рассматривала «баснословие» фольклора как синоним абсолютной недостоверности. Этот подход был унаследован так называемой мифологической школой конца XIX - XX в. 
Аля ее представителей мифологическое осмысление реальности в устной традиции само по себе закрывало вопрос о какой-либо ее «исторической основе». С другой стороны, на волнах «национал-романтизма» первой половины XIX в. сформировалась «историческая школа». Ее представители, находя те же самые фольклорные элементы в раннеписьменной традиции, рассматривали вместе с тем эпос и предание как вполне достоверную в основе «устную хронику». Аля них устное происхождение того или иного эпизода служило основанием не для отнесения к «мифологии», а напротив, для поиска «исторической основы». Стоит еще отметить, что среди «мифологистов» очень быстро стали преобладать филологи, а «историзм» оказался ближе историкам (или, точнее, решаемым ими задачам общеисторической реконструкции).

Без этой предыстории не вполне ясным оказывается генезис современного состояния методологии вопроса. Определенная усталость от полуторавековой дискуссии «мифологистов» и «истористов» естественным образом толкала к поиску новых подходов. Синтетические же подходы, по-своему успешные (Lord, 1960; Vansina, 1965; Азбелев, 1982; Foley, 1988), оставляли иллюзию победы «истористов» - поскольку подразумевали допущение «исторической основы». К этому добавилось обострение дискуссии об «авторском» и «коллективном» творчестве, поставившее под сомнение само понятие устной традиции.

Между тем в XX в. производимые «истористами» реконструкции дописьменного национального прошлого нередко использовались в идеологических целях. Такое официозное применение не могло добавить популярности ни классической «исторической школе», ни «синтезу» в мировой науке. Итогом стал расцвет сугубо «филологических》 и «текстологических» методик, переключивших внимание на текст конкретных памятников, их литературные корни. При чисто литературном происхождении того или иного считавшегося «фольклорным» сюжета вопрос о его «исторической основе» отпадал сам собой. Таким образом, современная научная ситуация во многом сформирована вненаучными, социально-психологическими факторами.

Предпринимаемое исследование отражения устной традиции в древнейших памятниках славяноязычной литературы призвано предложить авторское решение в том числе и методологических проблем. Перспективы видятся убедительными, также благодаря достижениям последних лет в изучении иных этнокультурных традиций, в том числе и российской наукой (Аревнейшие государства ..., 2013). Несколько весьма ценных работ посвящено собственно рассматриваемой теме (Щавелев, 2007; Белова, Петрухин, 2008). Занимались ею и авторы (Алексеев, 2006; Плотникова, 2015). В настоящей статье мы попытаемся очертить основные сформировавшиеся подходы.

\section{ТРАДИЦИОННАЯ МЕТОАИКА}

В мировой исторической и литературоведческой науке устная традиция определяется обычно как передаваемая изустно (прежде всего в форме повествовательных жанров фольклора) информация о прошлом. В качестве основных жанров устной традиции рассматриваются историческое, историко-родословное предание и эпическое сказание.

Аля вычленения элементов устного происхождения в письменных памятниках в науке традиционно используются следующие методы:

1) источниковедческий анализ происхождения тех или иных сведений в нарративных памятниках (прежде всего о ранней истории). В прошлом (а отчасти и в настоя- 
щее время) он часто применялся как «метод исключения». Информация, которая не могла быть получена прямо из источников письменных и не является явным домыслом, принималась как «устная». Более бесспорными являются случаи с прямыми ссылками авторов на устные источники информации. Например, первые русские летописцы неоднократно ссылаются на то, что «говорят», иногда называют конкретные источники устно полученных сведений (Полное собрание русских летописей, 1997: 9-10, 111, 281; Полное собрание русских летописей, 2000: 103, 109);

2) анализ жанровых особенностей целых памятников (например, эпического характера) и отдельных фрагментов. Памятники непосредственно воинского эпоса ( «Слово о полку Игореве», польская латиноязычная «Песнь Мавра») в книжность славянских народов вошли не ранее конца XII в. Однако следы устных памятников дружинного эпоса обнаруживаются, например, в том же начальном русском летописании. Жанровые черты такого рода видят в описании похода князя Олега на Константинополь, войн Ольги и Святослава. Аругим характерно отразившимся в раннем историописании жанром является топонимическое предание (об основании Киева, Переяславля);

3) сопоставление сюжетов и мотивов, отмеченных в письменных памятниках, с фольклорными сюжетами и мотивами. Воспроизводство в живом бытовании встречающихся в повествовательных памятниках Средневековья мотивов - не редкость. Вместе с тем следует с некоторой осторожностью относиться к совпадениям особенно конкретных сюжетов. Нередко фольклорные сюжеты имели своим источником литературное влияние. В ранней фольклористике к тому же встречалось активное вмешательство собирателей. При записях (вернее, пересказах) прозаических местных преданий, например, не раз отмечена подгонка слышанного под собственные представления;

4) выявление стилистических и лексических особенностей, сближающих письменный памятник или его фрагменты с фольклором. Например, в повествовании о браке Владимира и Рогнеды из начальной русской летописи отчетливо заметен эпический стих наподобие используемого в «Слове о полку Игореве» (Начальная летопись, 1999: 127-128). Приемы фольклорного сказительства, вероятно, оказали влияние на наиболее яркого представителя ранней сербской агиографии - Феодосия Хиландарца (см.: Алексеев, 2016).

\section{ФОАБКАОР И РАННЯЯ АИТЕРАТУРА:}

\section{ЖАНРОВАЯ ПРИРОАА И МЕТОДОАОГИЧЕСКИЕ САОЖНОСТИ}

А. С. Михачев метко сказал: «...судить о народном творчестве ХІ и предшествующих веков мы можем только по его остаткам в письменности. Только современные самим произведениям народного творчества их отражения в письменности дают нам возможность более или менее твердо судить о том, какими они были» (Аихачев, 1987: 147). Известный фольклорист и знаток этнографии В. Я. Пропп более категоричен в рассуждениях о месте и роли фольклора в ранних славяноязычных произведениях: «Ранняя, первая литература сплошь или почти сплошь есть фольклор... Правда, это не просто фольклор, а фольклор в отражениях и преломлениях... То, что происходит с фольклором и литературой на этой стадии развития, полно величайшего значения Аля понимания истории духовной культуры вообще» (Пропп, 1976: 31).

На наш взгляд, данная точка зрения не отражает истинного положения вещей. После принятия христианства и распространения единой письменности у восточных сла- 
вян, болгар, сербов, а позже и румын появился комплекс единой литературы. Единый фонд церковнославянской литературы, сложившийся в X-XII вв., представлен проповеднической, церковно-назидательной, агиографической, всемирно-исторической литературой. Здесь в силу своих жанровых особенностей и церковного этикета не было места для фольклорных элементов. Устное народное творчество нашло себе место прежде всего в повествовательной литературе, которая в количественном соотношении первое время сильно проигрывала церковной. Однако, по мере того как церковные нужды в литературе удовлетворялись и книжники все в большей мере переходили от переводов к написанию оригинальных сочинений, в них-то и находило себе место устное народное творчество. Фольклорные элементы обнаруживаются в таких жанрах древней литературы, как летописи, повести, сказания. Есть отголоски устного творчества и в различных «Словах», а также в житиях монархов. В произведениях этих жанров устное творчество тесно переплетено с христианской риторикой, отчего в них появляются особый колорит и глубокая сакральная нагрузка.

За более чем двухсотлетний период существования фольклористики учеными был накоплен огромный багаж по проблеме взаимосвязи фольклора и литературы. Однако далеко не все работы способствовали расширению знаний в этой области. Напротив, некоторые из них вводили последующие поколения ученых в заблуждения. И это связано не только с противоречиями между литературоведами, фольклористами и историками и различиями в их подходах к исследованию самой проблемы, но также и с разностью методик исследования. Основная сложность, на наш взгляд, заключается в том, что многие исследователи слишком мало уделяли внимания основополагающим принципам построения устных и литературных произведений. В то же время эти принципы совершенно различны, и их совмещение или неверное определение приводят к восприятию фольклорных элементов в качестве цитат из переводных сочинений, и наоборот.

В процессе исследования фольклорных әлементов в тексте литературного произведения важно учитывать, что устное произведение всегда строится по системе образности. Оно всегда обращено к слушателю своей эмоциональной стороной. Слушатель должен воспринимать образы и скрытую в них смысловую нагрузку сердцем. В то же время литературное произведение подчинено другому началу - логике. Здесь у каждой причины есть следствие, а читатель, - заметим, не слушатель, - читая произведение, уже не слышит его мелодию, ритм, не создает себе образные картины, продиктованные во многом мелодией и даже самой выразительностью напева, тембром голоса. Читатель зрительно воспринимает буквенные символы, складывает их в слова и воспринимает смысл прочитанного. Именно поэтому в литературных произведениях на первом плане многоуровневая содержательная нагрузка, а не система образов.

Соединение в одном литературном произведении фольклорных әлементов, библеизмов, различных цитат из переводной литературы представляет большую сложность в изучении не только в связи со сложностью разведения всех этих элементов, но и в связи с неоднозначностью восприятия такого произведения самими исследователями. Так, например, В. П. Адрианова-Перетц, глубокий знаток древнерусской литературы, считала, что фольклорные элементы, обнаруживаемые в древних литературных произведениях, слишком гиперболизированы. В частности, она писала:

«Установление внутреннего родства древнерусской литературы, в ее лучших образцах, с фольклором вскрывает характер ее народности. Исследование связи лите- 
ратуры и фольклора, независимой от какого бы то ни было прямого «влияния» и выражающейся в общности их отношения к действительности, приводит к вопросу о сходстве самого художественного метода отражения этой действительности у писателя и народного поэта... Некоторым памятникам литературного эпоса, как и устному эпосу русского Средневековья, одинаково свойственна гиперболизация действительности, за которой стоит определенная оценка реальных фактов. Этот своеобразный метод художественного отражения действительности выполняет раздичные функции и должен быть изучен во всех его многообразных проявлениях как в литературе, так и в фольклоре. Образы князей “Слова о полку Игореве”, к которым обращается автор с призывом выступить “за землю Русскую”, представлены с блестящим знанием политической обстановки конца XII в., и вместе с тем они гиперболизированы, чтобы подчеркнуть силу, могущество, власть этих князей, - все то, что должно было, по мысли автора, объединиться для борьбы с наступавшей “степью”. Гиперболизированные воинские картины усиливают впечатление от трагического столкновения русских дружин с половецкими войсками» (Адрианова-Перетц, 1974: 10).

Уже с современных исследовательских позиций по данной проблеме хотелось бы уточнить один момент. «Гиперболизированность» - не простая условность, а художественный метод, широко применяемый в народном творчестве, о чем писала и сама В. П. Адрианова-Перетц. Этот метод вслед за народными сказителями стал использоваться и средневековыми авторами в своих произведениях. Народному автору и создателю литературного произведения вряд ли мог быть свойственен один взгляд на происходящее. Вероятнее всего, писатель в создании сюжетной линии и образов своего сочинения использовал типовые шаблоны из устных произведений, в первую очередь с целью усиления впечатления от написанного, а также для правильного его понимания читателями.

Сегодня исследователям уже хорошо известно, что каждый «гиперболизированный» образ нес в себе определенную «зашифрованную» смысловую нагрузку, понятную для современников и не понятную для потомков. Аанное утверждение хорошо раскрывается с помощью фольклорных образов и эпитетов, приведенных в «Задонщине». «Черна земля под копытами, костями татарскими поля усеяны, а кровью их земля залита...»- так в аллегоричной форме передается трагизм ситуации и эмоциональное состояние современников, свидетелей событий. Собирательный образ добра, света, русского воинства передан в произведении через аллегорию с птицами, образ которых имел положительное сакральное значение для славян - «соколы, кречеты и белозерские ястребы», в то время как татарские воины - враги, губители Земли Русской показаны в произведении в образе птиц - предвестников беды и сил мрака — «несметные стада гусиные и лебединые» (см.: Задонщина, 1999).

На наш взгляд, именно в силу того, что каждый образ фольклорного произведения собирателен и вмещает в себя целый набор характеристик, позволяющий автору в нескольких словах передать всю глубину происходящего, описания, создаваемые с помощью таких образов и размещенные в ранних литературных произведениях, выглядят для нас гиперболизированными, что только подчеркивает их высокий уровень. Гиперболизированность фольклорных образов, обнаруживаемых в древних памятниках славянских литератур, объяснима еще одной особенностью фольклора: стихотворный славянский фольклор всегда поется. Именно поэтому фольклорные эпические элементы в отрыве от музыки и в контексте литературного сочинения выглядят несколько вычурно и гиперболизированно. 
По этому поводу В. Я. Пропп писал: «...изучать фольклор вне связи с музыкой значит понимать только половину дела... Текст и напев составляют одно органическое целое, и метрика стиха не может изучаться вне музыкального ритма и голосоведения. Русские песни, кроме хороводных, игровых и плясовых, не делятся на строфы. Текст не показывает строф, их покажет мерно повторяющийся напев. Песня иногда имеет скрытое строфическое строение, что может оказаться важным для ее жанрового определения и изучения ее происхождения или исконных форм. Так обстоит дело с классическим героическим эпосом: к нему относятся только такие произведения, которые поются. Так, сюжет о встрече Ильи Муромца с Соловьем-разбойником дибо поется - и тогда он относится к области эпоса, либо рассказывается - и тогда это народная проза, представляющая собой или сказку, или повествование литературнокнижного характера» (Пропп, 1998: 36).

В изучении фольклорных элементов в составе древних литературных памятников больших результатов достиг А. С. Аихачев. В частности, ученый обратил внимание на прямую и неразрывную связь образа героя и подвига, им совершенного: «И вот замечательно, что из произведений народного творчества летописцы заимствовали не только исторические факты, но и самые образы их героев. $<\ldots .>$ Герой народного эпоса это человек богатырского подвига. $<\ldots . .>$...образ героя неотделим от совершенного им исторического подвига, запечатлевшегося в памяти народа» (Иихачев, 1987: 142).

Стоит отметить, что в фольклорных произведениях, получивших свое дальнейшее развитие в литературе, не только образ героя привязан к подвигу, но и вообще любой образ связан с вполне конкретной характеристикой чего-либо. Именно верная «расшифровка» того или иного образа помогает понять читателю, а вместе с ним и исследователю, эмоциональную нагрузку произведения, а также авторское восприятие описываемого события. Здесь нельзя не согласиться с Т. Н. Ажаксон, которая писала: «Одна из особенностей мышления человека - представлять все явления и процессы окружающей жизни в виде антиномических пар, что имеет свое основание в таких действительно существующих и важных для человека оппозициях, как жизнь и смерть, мужчина и женщина, Солнце и $А$ уа, свет (день) и тьма (ночь), холод (зима) и тепло (лето) и т. А.» (Ажаксон, Коновалова, Подосинов, 2013: 68).

Очевидно, что эффективная работа по вычленению элементов устной традиции из письменных памятников может быть основана на сочетании методов филологических и источниковедческих. Среди первых ключевое значение имеет исследование особенностей эпической «речи». Вычленение элементов, заведомо не имеющих книжного прототипа, в древнейших сочинениях исторического содержания, сохраняет свою продуктивность. Но к критериям выделения таких элементов историку-источниковеду нового поколения следует подходить с гораздо большей тщательностью.

Сводное исследование, учитывающее достижения обеих научных традиций, на сегодняшний день в отечественной науке отсутствует. Не проводилось также обобщающего сопоставительного анализа восточнославянской и южнославянской традиций. Между тем относительное единство культурного и литературного пространства, постоянная коммуникация славяноязычных литератур Средневековья делают такой анализ возможным и полезным. Отражение фольклора в книжности рассматривается как важнейший элемент истории формирования средневековой славянской литературы и культуры. Полноценное использование современных методов и подходов на максимально возможном уровне обобщения в итоге приведет к реальному приращению нового научного знания. 


\section{СПИСОК АИТЕРАТУРЫ}

Адрианова-Перетц, В. П. (1974) Аревнерусская литература и фольклор. $\Lambda$. : Наука. 209 с.

Азбелев, С. Н. (1982) Историзм былин и специфика фольклора. $\Lambda$. : Наука. 327 с.

Алексеев, С. В. (2006) Предания о дописьменной эпохе в истории славянской культуры XI-XV вв. М. : Национальный институт бизнеса. 412 с.

Алексеев, С. В. (2016) Памятники сербской средневековой историографии XIII-XVII вв. Переводы и исследование : в 2 т. СПб. : Петербургское востоковедение. Т. 1. Жития святых Симеона и Савы. Жития королей и архиепископов сербских. 720 с.

Белова, О. В., Петрухин, В. Я. (2008) Фольклор и книжность: миф и исторические реалии. М. : Наука. 280 c.

Ажаксон, Т. Н., Коновалова, И. Г., Подосинов, А. В. (2013) Античность и средневековье. М. : Рукописные памятники Аревней Руси. 422 с.

Аревнейшие государства Восточной Европы (2013). 2011. Устная традиция в письменном тексте / отв. ред. Г. В. Глазырина. М. : Университет Амитрия Пожарского. 592 с.

Задонщина (1999) / пер. и комм. А. А. Амитриев // Библиотека литературы Аревней Руси / отв. ред. А. С. Аихачев, А. А. Амитриев, А. А. Алексеев, Н. В. Понырко. СПб. : Пушкинский дом. T. 6: XIV - середина XV века. 583 с. С. 120-136.

Иихачев, А. С. (1987) Человек в литературе Аревней Руси // Иихачев, А. С. Избранные работы : в 3 т. $\Lambda$. : Художественная литература. Т. 3. 520 с. С. 3-159.

Начальная летопись (1999) / пер. и комм. С. В. Алексеева. М. : Историко-просветительское общество. 186 с.

Плотникова, О. А. (2015) Рождение русской словесности. М. : Вече. 288 с.

Пропп, В. Я. (1976) Фольклор и действительность. М. : Наука. 325 с.

Пропп, В. Я. (1998) Поэтика фольклора. М. : Аабиринт. 352 с.

Полное собрание русских летописей (1997). М. : Языки русской культуры. Т. 1. Ааврентьевская летопись. 732 с.

Полное собрание русских летописей (2000). М.: Языки русской культуры. 692 с. Т. 3. Новгородская первая летопись старшего и младшего изводов.

Щавелев, А. С. (2007) Славянские легенды о первых князьях. М. : Северный паломник. 272 с.

Foley, J. M. (1988) The Theory of Oral Composition: History and Methodology. Bloomington : Indiana University Press. $170 \mathrm{p}$.

Lord, A. B. (1960) The Singer of Tales. Cambridge, MA : Harvard University Press. 309 p.

Vansina, J. (1965) Oral Tradition. A Study in Historical Methodology / Transl. by H. M. Wright. London : Routledge \& Kegan Paul. 226 p.

Аата поступления: 25.04.2017 2.

\section{REFLECTION OF THE FOLK EPIC AND THE HISTORY TALES IN THE OLDEST MONUMENTS OF SLAVIC LITERATURE: TO THE METHODOLOGY OF IDENTIFICATION \\ S. V. Alekseev, O. A. Plotnikova \\ Historical and EDUCATIONal Society "RAdetel", Moscow}

The paper is dedicated to the methods of separating the elements of oral origin in written monuments. Its aim is to overview the methods which are known in science drawing on the corpus of the Slavic literatures of the early Middle Ages, and to determine the extent of their implementation from the viewpoint of the modern scientific knowledge. Science traditionally utilizes the source study analysis of the origin of various information in narrative monuments (first of all, about early history); the analysis of genre features of entire monuments (for example, of an epic nature) and individual fragments; the comparison of plots and motifs presented in written monuments, with folklore plots and motifs; the identification of stylistic and lexical features that bring together a written monument or its fragments with folklore. At the same time, studies of recent decades have shown the weaknesses of a straightforward simplistic approach to the identification of folklore elements in medieval Slavic literature, the likelihood of the bookish origin of many plots and motifspreviously categorically classified as folklore. 
Attention is drawn to the narrowness of the boundary separating literary creativity from oral-epic (the absence of conscious authorship at the early stages of development of literature, common for the early literature and folklore mechanisms of assimilation of the reality to the ideal and exemplary). All this encourages researchers who focus on the oral sources of Slavic literature to adjust their methodology and take into account the achievements of colleagues - above all, this refers to the need for more rigorous research of texts of foreign origin that were or could have been sources for Slavic bookmen.

More precise criteria for separation of the elements of the oral tradition from written monuments can only be based on the combination of philological methods (the study of the features of epic «speech») and source studies (the separation of elements that are not known to have a book prototype in the oldest works of historical content).

Keywords: folk epic; history tale; oral tradition; folklore; Old Russian literature; South Slavic literature; Middle Ages; chronicles; biographies; source study

\section{REFERENCES}

Adrianova-Peretc, V. P. (1974) Drevnerusskaja literatura i fol'klor. Leningrad, Nauka. 209 p. (In Russ.).

Azbelev, S. N. (1982) Istorizm bylin i specifika fol'klora. Leningrad, Nauka. 327 p. (In Russ.).

Alekseev, S. V. (2006) Predanija o dopis' mennoj jepobe v istorii slavjanskoj kul' tury XI-XV vv. Moscow, Nacional'nyj institut biznesa. 412 p. (In Russ.).

Alekseev, S. V. (2016) Pamjatniki serbskoj srednevekovoj istoriografii XIII-XVII vv. Perevody i issledovanie. T. 1. Zhitija svjatyb Simeona i Savy. Zhitija korolej i arbiepiskopov serbskih. St. Petersburg, Peterburgskoe vostokovedenie. 720 p. (In Russ.).

Belova, O. V. and Petruhin, V. Ja. (2008) Fol'klor i knizhnost': mif $i$ istoricheskie realii. Moscow, Nauka. 280 p. (In Russ.).

Dzhakson, T. N., Konovalova, I. G. and Podosinov, A. V. (2013) Antichnost' i srednevekov' e. Moscow, Rukopisnye pamjatniki Drevnej Rusi. 422 p. (In Russ.).

Drevnejshie gosudarstva Vostochnoj Evropy (2013). 2011. Ustnaja tradicija v pis' mennom tekste/ ed. by G. V. Glazyrina. Moscow, Universitet Dmitrija Pozharskogo. 592 p. (In Russ.).

Zadonshhina (1999) / transl. and comm. By L. A. Dmitriev. In: Biblioteka literatury Drevnej Rusi./ ed. by D. S. Lihachev, L. A. Dmitriev, A. A. Alekseev and N. V. Ponyrko. St. Petersburg, Pushkinskij dom. Vol. 6: XIV - seredina XV veka. 583 p. (In Russ.).

Lihachev, D. S. (1987) Chelovek v literature Drevnej Rusi. In: Lihachev, D. S. Izbrannye raboty. Leningrad, Hudozhestvennaja literatura. Vol. 3.520 p. (In Russ.).

Nachal'naja letopis' (1999) / transl. and comm. by S. V. Alekseev. Moscow, Istorikoprosvetitel'skoe obshhestvo. 186 p. (In Russ.).

Plotnikova, O. A. (2015) Rozbdenie russkoj slovesnosti. Moscow, Veche. 288 p. (In Russ.).

Propp, V. J. (1976) Fol'klor i deistvitel' nost'. Moscow, Nauka. 325 p. (In Russ.).

Polnoe sobranie russkih letopisej (1997). Moscow, Jazyki russkoj kul'tury. Vol. 1. Lavrent'evskaja letopis'. 732 p. (In Russ.)

Polnoe sobranie russkih letopisej (2000). Moscow, Jazyki russkoj kul'tury. Vol. 3. Novgorodskaja pervaja letopis' starshego i mladshego izvodov 692 p. (In Russ.).

Shhavelev, A. S. (2007) Slavjanskie legendy o pervyh knjaz’jah. Moscow, Severnyj Palomnik. 272 p. (In Russ.).

Foley, J. M. (1988) The Theory of Oral Composition: History and Methodology. Bloomington, Indiana University Press. $170 \mathrm{p}$.

Lord, A. B. (1960) The Singer of Tales. Cambridge, MA, Harvard University Press. 309 p.

Vansina, J. (1965) Oral Tradition. A Study in Historical Methodology / transl. by H. M. Wright. London, Routledge \& Kegan Paul. 226 p. 
Алексеев Сергей Викторович - доктор исторических наук, профессор, председатель Историко-просветительского общества «Радетель», главный редактор издательства «Кучково поле - Музеон». Адрес: 123098, Россия, г. Москва, ул. Маршала Василевского, д. 9, корп. 5. Tел.: +7 (499) 190-52-65.E-mail: ipo1972@mail.ru

Плотникова Ольга Анатольевна - доктор исторических наук, доцент, заместитель председателя Историко-просветительского общества «Радетель». Адрес: 123098, Россия, г. Москва, ул. Маршала Василевского, д. 9, корп. 5. Тел.: +7 (499) 190-52-65. E-mail: monomach@list.ru

Alekseev Sergey Viktorovich, Doctor of History, Professor; Chairman, «Radetel», Historical and Educational Society; Editor-in-Chief, "Kuchkovo Pole - Museon" Publishing House. Postal address: 9, Bldg. 5, Marshala Vasilevskogo St., Moscow, Russian Federation 123098. Tel.: +7 (499) 190-52-65. E-mail: ipo1972@mail.ru

Plotnikova Olga Anatolievna, Doctor of History, Associate Professor, Vice-Chair, «Radetel», Historical and Educational Society. Postal address: 9, Bldg. 5, Marshala Vasilevskogo St., Moscow, Russian Federation 123098. Tel.: +7 (499) 190-52-65. E-mail: monomach@list.ru 